\title{
Commentary
}

\section{Supporting speech and language therapy students in uncertain times}

\author{
Emma Gregory*, Judy Clegg and Helen Cameron \\ Division of Human Communication Sciences, University of Sheffield, Sheffield, England, UK
}

Received 30 June 2021

Accepted 15 November 2021

\begin{abstract}
The COVID-19 pandemic has impacted significantly on the provision of speech and language therapy education. In this commentary, we consider the impact of unprecedented uncertainty and disruption on the student experience. Changes made within both university and practice-based learning environments have resulted in the continuation of high-quality learning experiences enabling students to continue or complete their programmes. However, studying in uncertain times has been destabilising for students having the potential to impact on the more nuanced aspects of clinical and professional development (e.g., self-efficacy, confidence, and professional identity formation). We reflect on collaborative efforts to support students with navigating uncertainty and change and to facilitate their ongoing personal, professional and clinical development in a holistic way. There is a need for empirical research into the experiences of student speech and language therapists who have studied or are continuing to study in the context of COVID-19. Such research will help inform university and practice-based educators as well as speech and language therapy managers about the ongoing needs of this population. Dealing with uncertainty should be considered within university-based curriculum development as well as induction and supervisory systems within the workplace.
\end{abstract}

Keywords: Speech and language therapy, education, uncertainty, professional identity, COVID-19

\section{Introduction}

The coronavirus (COVID-19) pandemic has impacted significantly on the provision of speech and language therapy (SLT) education across both university and practice-based learning environments. In March 2020, SLT students training in England began to be withdrawn from placements and faceto-face university-based learning rapidly moved to online platforms. Since then, students have experienced a prolonged period of disruption, uncertainty and flux. Both Practice Educators (PEs) supervising SLT students on placement and Higher Education

\footnotetext{
${ }^{*}$ Corresponding author: Dr. Emma Gregory, Senior University Teacher \& Director of Professional Education, Health Sciences School, Division of Human Communication Sciences, The University of Sheffield, 362 Mushroom Lane, Sheffield, S10 2TS, UK. Tel.: +44 0114 2222417; E-mail: emma.gregory@ sheffield.ac.uk.
}

programme providers have demonstrated their ability to innovate beyond all expectations. Professional, regulatory and commissioning bodies in England (Royal College of Speech and Language Therapists, Health and Care Professional Council, Health Education England) worked together to support placement providers and universities to continue to provide high-quality experiences for students whose learning appeared to be under threat. Although the impact of COVID-19 on healthcare education is ongoing, we propose it is important to reflect on the changes to the context of SLT training so far and to identify key learning points.

Naturally, some of these reflections are on the obvious and observable modifications to healthcare education delivery. SLT educators within universities and healthcare services are now sharing innovative methods for the development of students' knowledge 
and clinical skills via virtual or hybrid placements (e.g. Rogers \& Duffy, 2021; Royal College of Speech and Language Therapists, n.d.) and there is an emerging body of literature reporting developments across the allied health professions (Salter, 2020; Twogood et al., 2020). The student perspectives of learning within these new placement models are also beginning to be documented (e.g. McCormack, 2021; Sandiford et al., 2021).

The focus of this commentary, however, will be on the impact of the pandemic and subsequent changes on the more nuanced, less tangible aspects of student development. For example, the potential impact of uncertainty and change on student self-efficacy and confidence, on development of professional identity and on their sense of belonging in the broader SLT community. We reflect on the efforts of Higher Education providers and PEs to facilitate students' continued growth in these areas using case examples from within our pre-registration undergraduate and postgraduate SLT programmes within a specific university educational context in England. Ethical approval from the host university was granted to carry out this information gathering.

\section{The unknowns of speech and language therapy training during a pandemic}

Whilst university learning should rightly bring novelty and challenge, in usual times student SLTs are arguably able to make certain predictions about their university and practice-based learning environments. For example, such predictions would include, studying with peers in physical spaces, developing social and collaborative support networks, understanding that technologies will enhance but not dominate learning, and that on placement they will transition from observation and guided hands-on experience to autonomous practice. The impact of the COVID-19 pandemic meant that these 'knowns' had shifted, and uncertainty, novelty and challenge now applied to all areas of their learning.

The unknowns were plentiful. There was initial uncertainty around when placement and teaching would recommence and what form they would take when they did. There were logistical and technological barriers to overcome to begin delivery of the academic curriculum online and PEs were grappling with the significant impact of COVID-19 on services and their own transition to remote provision.
Students were left unsure about next steps and the impact on their progression. At the same time, along with the rest of the population, students faced uncertainty in all other aspects of their lives. Studying from their homes, many lacked their usual support systems. International students were presented with travel restrictions, student caregivers were faced with school closures and students may have been worried for their - or their family's - health. The impact on student experience and wellbeing was significant (Evans et al., 2021).

Although some areas of impact have been universal, the SLT student experience has differed across individuals and in relation to their point of study. For final year students graduating in 2020, early concerns voiced within the university environment centred around being safe on placements, completing competences, and entering the workforce during such a time of turmoil. As the pandemic has endured, similar concerns about the future have been expressed by students nearing graduation. As part of a module during Spring 2021, students created a 'worry board' reporting their present primary concerns. The most common posts on the virtual whiteboard related to 'confidence'. Confidence in being competent enough to complete the programme, in securing a first post and in being able to do the job if successful. Students referred to the feeling of not being sufficiently prepared for the transition to clinical practice. They voiced concerns about manager expectations and whether supervision within the job would be sufficient. Such concerns are by no means new and are often voiced by students approaching the transition to working life (Brumfitt et al., 2005). However, it is clear that such feelings may be amplified in the current context and that, for some, confidence in competence has been impacted.

At the other end of the learning journey, cohorts of students have commenced their SLT training within this changed context. At the time of writing, many of these students have still not experienced their previously anticipated learning environments and the communities within these. In usual times, induction into and gradual immersion in these new communities helps healthcare students to bond, to develop an understanding of the world of study and the world of their chosen profession, and to begin to develop their professional identity (Goldie, 2012; Komarraju et al., 2010). With learning environments and communities radically impacted, so were opportunities for students to develop a sense of themselves within these contexts. 


\section{Professional identity and communities of practice}

Professional identity formation has been widely discussed in the fields of psychology, education and healthcare (Cruess et al., 2014; Henkel, 2005; O'Leary \& Cantillon, 2020). To adapt a phrase from the medical literature and apply to our context, we can conceive professional identity formation as how learners come to 'think, act, and feel like a...' speech and language therapist (Cruess et al., 2014, p. 1446). Professional identity formation is a gradual, fluid and flexible process which many perceive as a socio-cultural phenomenon that confers a sense of belonging (Henkel, 2005, 2009). In this view, identity is not fixed within the person but formed, shaped, and reshaped through interactions with others and the communities the individual operates in, referred to as communities of practice (Henkel, 2009; Lawler, 2014; Wenger et al., 2002). A community of practice is a group of people "who share a concern, a set of problems or a passion about a topic and who deepen their knowledge and expertise in this area by interacting on an ongoing basis" (Wenger et al., 2002, p. 4). Part of what communities of practice provide in professional education is the less tangible learning, that is, learning that is less visible than knowledge and competency acquisition.

In terms of clinical learning, engagement in SLT communities of practice exposes students to the "tacit knowledge embedded in the profession, the prevailing ideological and theoretical perspectives, the unconsciously accepted aspects of professional practice and the culture of the professional" (Stokes \& McCormick, 2015, p. 2). A student learns much through observation and absorption, by being in the presence of a range of speech and language therapists, watching them interact with their environment and those within it, hearing them talk not just about their clients but their professional views and beliefs or about how they tackle complex issues. Students are also exposed to shared learning from errors or when clinical practice does not go as planned. In placements during COVID-19, students have continued to engage and interact with SLTs and other healthcare and education professionals. However, the degree of exposure to, depth of immersion in, and the diversity of these communities has differed from what they might have experienced in 'usual' times. As Quigley et al. (2020) state, the ideal is for "multiple opportunities to apply academic theory to clinical practice, to develop discipline-specific and cross-disciplinary skills, to socialise into their chosen profession, and to hone relevant interpersonal, clinical reasoning and management skills" (p. 507). In 2020 and 2021, the gradual accumulation of experience through placement has been disrupted for many students.

University-based communities are similarly important for engagement and connection, and access to the more hidden ways of knowing and doing, which ultimately result in changes in knowledge, understanding and behaviour (Mathieson, 2014). Beyond the benefits of active learning in a group environment, students are able to 'test out' their learning within peer communities, with opportunities to learn from success and error. Students compare learning and placement experiences, exchange knowledge, update their understanding and seek, or provide, reassurance. For students at all stages of study, these daily interactions decreased and with them opportunities for calibration, support, and social learning. It was likely that both the process of 'becoming' a speech and language therapy student, and 'becoming' a speech and language therapist had been altered for those at the beginning and those nearing the end of their programmes. The question facing Higher Education providers was how to address this.

\section{Case examples of practice}

Within this section we describe ways in which in our own educational university context, we attempted to create: a) an infrastructure, with new methods of communication, aiming to provide some stability within our students' radically altered learning environment; b) opportunities for students to develop their ability to deal with stressful challenges; and c) access to communities which might facilitate a continued sense of connection and belonging to the programme and profession.

\subsection{Communication and infrastructure}

Core to this transformation was the rapid establishment of accessible, transparent means of communication and information transmission. There is evidence to suggest that with shared knowledge and a culture of openness comes an enhanced feeling of control, resilience, adaptability, trust and ability to cope with stressors (Nelson et al., 2021). Our Head of Division commenced weekly student email updates bringing together key points from multiple communications that students received with clear signposting 
to departmental and university support services. Distilling key information in a concise way mitigated against adding to information overload in a time of stress (Gelles et al., 2020). Within these communications, as well as taking a compassionate approach to acknowledging the challenges all were facing, it was important to provide reassurance around how challenges were being addressed and focus on positive stories too (West, 2021). In addition, a central, online student query document was set up and provided a shared space for anonymised student queries from undergraduate and postgraduate programmes across all levels of study. Over 200 student queries relating to learning, teaching, placement, and wellbeing were posted between March 2020 and June 2021. Staff were able to monitor this online forum and provide open, honest and timely responses. Beyond sharing information, this online forum for communication was inclusive, collaborative and reassuring, enabling students to see that their peers had similar concerns (Clouder \& Deepwell, 2004; West, 2021). Students maintained regular interaction with staff through online learning and additional year group meetings. These provided multiple opportunities for communication, support and connection. The most frequently used term in student feedback about staff communication over this time was "supportive". One student praised staff for "maintaining communication, solving problems so creatively and being accessible". In many situations, our response to valid but unanswerable student queries would be 'we don't know but bear with us'. It was important for students to see that we were often 'in' the uncertainty with them but that we could hold that together. We were open and honest around the unknowns, acknowledging that in complex, unpredictable situations there was not always a recipe book approach to solving the dilemma. This strategy allowed us to model another way of dealing with uncertainty. As Clouder (2005) states, educators "do not possess ready answers and it is good that students see this is the case and that many issues are irresolvable" (p.514). Student feedback indicated the impact of the model set by staff. One student communicated gratitude for "the examples of professionalism, compassion and creativity the staff set for us", with another adding, "hopefully... this creativity will inspire our practice in the future." Clouder (2005) calls for educators in healthcare to steer students away from "trouble-free knowledge" and towards engagement with "messy realities" (p.513) these being more reflective of the workplace we are preparing them for. In some cases, we would engage students in problem-solving and critical and reflective thinking along with us. We presented options to students (e.g., around adaptations to teaching and assessment) but also encouraged them to generate their own solutions. Compassionate flexibility was important in recognising the hardships students were facing and making adaptations based on student preferences where possible (Gelles et al., 2020). Facilitating such open and constructive dialogue between educators and students can support students to maintain perspective in times of uncertainty as well as build relevant, real world skills for the professional life which awaits (Afrouz, 2021; Clouder, 2005).

\subsection{Strategies for dealing with uncertainty}

Beyond modelling strategies for dealing with uncertainty, we supported students to develop their own strategies for maintaining wellbeing and enhancing resilience. Ahern et al. (2008) describe resilience as an "adaptive stress-resistant personal quality that permits one to thrive in spite of adversity" (p. 32). As a concept it has received particular attention in the healthcare arena in recent years (Deeny \& Hardy, 2018; Delany et al., 2015; Johnson et al., 2020; Pettit et al., 2015). Dealing with uncertain or challenging situations is undoubtedly part of usual practice for SLTs. Complex and ethical decision making and reflection are core to clinical practice and well established in SLT programme curricula (Body \& McAllister, 2009). However, as Afrouz (2021) argues, uncertainty may produce different outcomes, depending on how an individual deals with the situations facing them. On the one hand, uncertainty could result in increased competitiveness, fear of risk and questioning of competence, potentially resulting in self-protection, narrowness, and rigidity. However, when supported to approach uncertainty in a different way, more positive outcomes such as opportunities for innovation, creativity, compassion and optimism become possible (Afrouz, 2021; Delany et al., 2015). In the context of the pandemic, we delivered wellbeing workshops based on the work of Delany et al. (2015) to all students. Delany et al. explored a four-session psycho-education program aimed to increase practical skills-based resilience capacities in physiotherapy students. As part of the programme, students learnt Cognitive-Behavioural Therapy principles (Beck, 2011; Ellis, 1980) and identified 'stressful challenges' experienced on placement (e.g., constant observation and assessment, getting things 
'wrong'). Students then worked through a process of exploring their beliefs about and responses to these challenges, generating associated resilience-based coping strategies. In our adapted training, students watched a pre-session video about resilience-based strategies, and then attended an online, two-hour workshop to learn the cognitive-behavioural model and practice applying this in small groups. They completed post-session wellbeing reflections and goal setting activities. It was important to communicate to students that we already recognised their existing resilience and to avoid overly focusing on individual responsibility fostering this attribute (Beirne, 2019; Chinn, 2018; Ewen, 2021). As Beirne (2019) states, resilience is a collective responsibility, it is systemic, and part of a culture of practice. We provided an online platform for students and staff to share their thoughts about resilience and top tips for managing wellbeing. The resulting posts were creative and inspiring, and provided support beyond the student group for staff members too. Engagement with students through these activities highlighted the limitations of what we could provide in a short space of time. Our resilience-training workshop lacked the continuity and focus on applying behavioural strategies that Delany et al. (2015) outlined. Providing input at a time where staff resilience was challenged and resources finite meant that we also failed to evaluate the changes we put in place. Going forward we recognise the need to a) provide more opportunities for students to apply their resilience skills to facilitate any meaningful change in coping strategies; and b) systematically evaluate the effectiveness of such a programme.

\subsection{Creating and reshaping communities}

In usual times, our students benefit from induction into a range of communities of practice involving active and peer learning. Communities of practice are not usually forged intentionally, rather they "emerge spontaneously whenever people come together to engage in any activity" (Mathieson, 2014, p. 69). Since March 2020, it has been important to reimagine our communities of practice, providing opportunities for communities to re-emerge.

\subsubsection{Student communities}

Aware of the potential impact of reduced social contact with peers we set up online peer support groups. All students were allocated to groups and provided with advice from how to arrange meetings, how often to meet, what to talk about, and establishing ground rules and boundaries. The value of peer support is well documented and in professional education prepares the student for newly-qualified practice (Markowski et al., 2021). It also aimed to compensate to some degree for the missed opportunities for chatting to each other in the hallway, discussing assignments over lunch, and finding 'their tribe'. Evaluation of student feedback indicated that this was the case. While students commented on practical benefits, (e.g., discussing placements, lectures and assignments), most comments related to the emotional and social support they conferred: a way of making friends at a time where it was socially challenging to do so, a safe space to share experiences and feel supported, reassurance that other people were feeling the same, and a space to feel of use to others. Quigley et al. (2020) state that where a student has reduced opportunity to imbibe learning through immersion in communities of practice "it is often difficult for a learner to fit in" (p. 514). However, comments indicated that these groups went some way to reducing isolation and fostering a sense of belonging. As one student stated: "it helps to feel that we are not alone". Our findings mirror benefits highlighted in studies exploring participation in peer support groups demonstrating that when peer support groups work, participants appear to thrive in them (e.g. Pereira et al., 2021; Peterson et al., 2008). In a small number of cases, these communities were less successful and consequently did not confer the same benefits. Some students reported that, rather than being reassuring, it could be stressful to hear the concerns of others particularly "when there is no resolution". One student commented that their group had never established, stating that this could "have a worse effect on those who haven't made their connections on their course elsewhere". Whilst some saw the flexibility and efficiency of online meetings, others felt this could not compensate for face-to-face contact. Additionally, challenges in managing group interactions online were referred to. Support for students in their induction into, management, and maintenance of peer support groups appears to be key. Exploring the differences between more and less successful groups would be a useful area of investigation in future.

\subsubsection{Practice-based communities}

The communities of practice within our university-based SLT clinic and external practice-based 
placements have undergone unprecedented disruption and a period of rebuilding. In usual times, the SLT clinic provides in-house voluntary and mandatory student placement opportunities with paediatric and adult populations. At the start of the pandemic, our clinic rapidly moved to telehealth delivery with multiple resulting benefits. Students continued their clinical experience while external placement providers dealt with the many challenges they faced prior offering placements again. It enabled innovations within current clinics and development of new clinics, responsive to population needs at the time. For example, in 2020, with visits to secondary school cancelled, and potential for increased anxiety around this transition for children with speech, language and communication needs (SLCN) (Gough Kenyon et al., 2020), the 'Moving up' project was established. Our SLT students collaborated with secondary schools and provided bespoke resources and video calls to children with SLCN approaching this transition (Spencer et al., 2021). Our SLT clinics enabled continued connection between students and staff, their peers, the clients they were able to continue supporting and to the profession they were passionate about. Students had the opportunity to feel part of a shared endeavour. Such opportunities for contribution beyond the level of the individual can act as protective factors in uncertain times (Nelson et al., 2021). As one student commented: "it's keeping me sane - I look forward to it".

In an attempt to bring even more of the outside clinical world into students' university learning environment, a virtual seminar series known as "SLT in the Spotlight" Series was launched in June 2020. Our students accessed seminars from over 25 clinicians from a variety of fields and backgrounds at different points in their career pathways. This allowed increased access to the richness and diversity of our profession, to practice wisdom and to connection with the broader community through narrative and discussion (Stokes \& McCormick, 2015).

When external placements recommenced, PEs also began to transform practice-based learning environments, pivoting to provide telehealth opportunities or hybrid placements where permitted. Regardless of placement type, student feedback has often referred to the framework PEs built to support student learning and the efforts to facilitate connection and inclusion: taking time to build rapport with students online; having established means of effective communication pre-, during and post-placement; providing a structured timetable at the outset and setting expectations; creating opportunities for reflection, feedback, and supportive supervision but also informal catch ups; providing opportunities for breadth of experience including engagement with multiple SLTs and the wider multidisciplinary team; PEs sharing their own experiences of this changed working environment. The feedback highlights active attempts to compensate for those incidental chats (e.g., in the car or lunchtime conversations in the staff room), and exposure to "personal reflections by seasoned practitioners" (Stokes \& McCormick, 2015, p. 6). Students appear to have particularly thrived where they have had meaningful opportunities to contribute and where their unique skills have been recognised and maximised (e.g., creating resources for families suddenly facing reduced provision, sharing their up-to-date evidence-based knowledge with teams). Through this professional inclusivity, PEs have continued to help students feel like a valued part of the future workforce, thus continuing to support professional identity formation (Nelson et al., 2021; Weaver et al., 2011). Sharing of less successful practice-based experiences from both PE and student perspectives has also been core to learning. Some of these less successful experiences included, for example, challenges around student access to IT, finding physical spaces for accommodating students, limited student access to clinical resources, and challenges in supporting independent work. In addition, whilst PEs have worked hard to create alternative communities for students to engage in, establishing rapport and developing relationships within these contexts has undoubtedly been a challenging experience (Sandiford et al., 2021).

\subsubsection{Enhancing broader communities}

For SLT and other Allied Health Professions' programme providers in England, Health Education England has been a key driver in influencing placement education, placement capacity and the workforce pipeline over this time. They have provided networks and support systems which are now bringing Higher Education providers and placement providers together to create new communities of practice (Council of Deans of Health, 2021; Health Education England, n.d.). This has allowed us to not only more effectively provide high quality placements for students but also to foster our PE/ Higher Education provider community. Within this network we will also continue to consider the important question 'what is a SLT placement?' Understandably, students envisage placements are with a qualified SLT 
in a setting where they can have face-to-face contact with clients and do 'something' with the clients. Our experiences show that the context and delivery of a placement can differ in many ways (e.g., the setting of the placement, who the professionals are who supervise the placement, and the types of client-student experiences). Ongoing discussion within our broader communities would support continued development of varied placements which centre competency development as a priority, rather than factors such as number of hours or other specific contextual factors.

\section{Conclusion}

Since March 2020, SLT programme providers have adapted to deliver curricula which continue to meet regulatory and professional requirements, and provide the requisite knowledge, skills, and approaches to learning to prepare students for the workplace. Students have experienced high quality placement experiences, albeit many of these altered from usual times. The rise to the challenge within the SLT profession and student community has been impressive. Although we would not have wished for the uncertainty and loss resulting from these times, we should rightly appreciate the resulting discoveries and the creativity, collaboration, and solution-focused approach demonstrated by all stakeholders.

We have provided a commentary focusing on our experiences within our own specific university and in some related practice-based environments in an English educational context. Our case examples describe changes made in the course of practice rather than data gathered as part of empirical research. Therefore, the specific scope of this commentary and the case examples cited, limit the depth of evaluation possible as well as the transferability of our experiences. It should be acknowledged that the limited student feedback we have presented is from those who elected to contribute. Some students did not actively participate in online synchronous discussions or contribute to evaluation. Whilst anonymity may have facilitated inclusivity to some degree, this potential participation bias means that we may not be representing the perspectives of a diverse range of students. Nonetheless, we hope that our thoughts provide a basis for others to explore some of the themes we raise further.

While this paper has focused on the student experience, we acknowledge that those who have graduated during this period will also have been impacted by the changes to their training. New graduates have long required and received support from the profession in their transition from semi-dependence to autonomous self-sufficiency (Brumfitt et al., 2005; O’Leary \& Cantillon, 2020). As a profession there needs to be recognition that the usual provision and support our new graduates receive, may need to be enhanced as they enter the workforce in these altered times. We know that professional identity formation is "a process not a destination" (Stokes \& McCormick, 2015 , p. 10). Wherever students and graduates are in this process, we can continue to facilitate this growth and their sense of belonging through our communities of practice. Within these communities, we must continue to focus on communication, leadership, wellbeing, connection and sharing of expertise and wisdom.

Moving forward there is a need for empirical research into the experiences of student SLTs who have studied or are continuing to study in the context of COVID-19. Such research will help inform university and practice-based educators as well as SLT managers about the ongoing needs of this population. Importantly, it should facilitate evidence-based integration of protective mechanisms within university programme delivery and in induction and supervision systems within the workplace. Although we hope that the level of uncertainty experienced in recent times will not persist long-term, healthcare students and professionals do need to be equipped to deal with the changing world we live in. As Stetson et al. (2020) observe, a pandemic "alters, impedes or accelerates" the process of professional identity formation ( $p$. 766). We have a collective responsibility to approach this crisis as an opportunity for transformation and growth.

\section{Acknowledgments}

The reflections in this paper are based on the work and achievement of the Human Communication Science Clinical Team including, alongside the authors: Sarah Spencer, Lucy Dyson, Caroline Haw, Catherine Tattersall, Carla Rohde, Janet Walmsley, Jen Whitfield, Ozge Ozturk, Emma Yarwood, Suzanne Churcher, Dee Webster and Dyan McKinley.

\section{Conflict of interest}

The authors have no conflict of interest to report. Given her role as an Editorial Board Member, Helen 
Cameron had no involvement nor access to information regarding the peer review of this article.

\section{References}

Afrouz, R. (2021). Approaching uncertainty in social work education, a lesson from COVID-19 pandemic. Qualitative Social Work, 20(1-2), 561-567. https://doi.org/10.1177/147332502 0981078

Ahern, N.R., Ark, P., \& Byers, J. (2008). Resilience and coping strategies in adolescents-additional content. Nursing Children and Young People, 20(10). https://doi.org/10.7748/paed2008. 12.20.10.1.c6905

Beck, J.S. (2011). Cognitive behavior therapy: basics and beyond (2nd ed.). Guildford Press.

Beirne, P. (2019). Building resilience: Supporting wellbeing for better outcomes [Workshop]. Royal College of Speech and Language Therapists Conference, Nottingham, UK.

Body, R., \& McAllister, L. (2009). Ethics in speech and language therapy. Wiley-Blackwell.

Brumfitt, S.M., Enderby, P.M., \& Hoben, K. (2005). The transition to work of newly qualified speech and language therapists: implications for the curriculum. Learning in Health and Social Care, 4(3), 142-155. https://doi.org/10.1111/j.1473-6861. 2005.00091.x

Chinn, T. (2018). Please don't call me 'resilient'. https://www. nursinginpractice.com/article/please-dont-call-me-resilient

Clouder, L. (2005). Caring as a 'threshold concept': transforming students in higher education into health(care) professionals. Teaching in Higher Education, 10(4), 505-517. https://doi.org/ 10.1080/13562510500239141

Clouder, L.D., \& Deepwell, F. (2004). Reflections on unexpected outcomes: learning from student collaboration in an online discussion forum [Paper presentation]. Networked Learning Conference, Lancaster, UK.

Council of Deans of Health. (2021). CoDH statement on student placements. https://www.councilofdeans.org.uk/2021/01/ codh-statement-on-student-placements

Cruess, R.L., Cruess, S.R., Boudreau, J.D., Snell, L., \& Steinert, Y. (2014). Reframing medical education to support professional identity formation. Academic Medicine, 89(11), 1446-1451. https://doi.org/10.1097/acm.0000000000000427

Deeny, K., \& Hardy, P. (2018). Resilience: A facilitator's guide http://www.patientvoices.org.uk/pdf/workbooks/DNAoC\% 20Resilience\%20r1.pdf

Delany, C., Miller, K.J., El-Ansary, D., Remedios, L., Hosseini, A., \& McLeod, S. (2015). Replacing stressful challenges with positive coping strategies: a resilience program for clinical placement learning. Advances in Health Sciences Education, 20(5), 1303-1324. https://doi.org/10.1007/s10459-0159603-3

Ellis, A. (1980). Rational-emotive therapy and cognitive behavior therapy: Similarities and differences. Cognitive Therapy and Research, 4(4), 325-340. https://doi.org/10.1007/BF011 78210

Evans, S., Alkan, E., Bhangoo, J.K., Tenenbaum, H., \& NgKnight, T. (2021). Effects of the COVID-19 lockdown on mental health, wellbeing, sleep, and alcohol use in a UK student sample. Psychiatry Research, 298(113819), 1-7. https:// doi.org/https://doi.org/10.1016/j.psychres.2021.113819
Ewen, C. (2021). There's more than one ' $i$ ' in resilience: Working together to support SLT resilience [Paper presentation]. Royal College of Speech and Language Therapists Conference, Virtual.

Gelles, L.A., Lord, S.M., Hoople, G.D., Chen, D.A., \& Mejia, J.A. (2020). Compassionate flexibility and self-discipline: Student adaptation to emergency remote teaching in an integrated engineering energy course during COVID-19. Education Sciences, 10(304), 1-23. https://doi.org/10.3390/educsci10110304

Goldie, J. (2012). The formation of professional identity in medical students: considerations for educators. Medical Teacher, 34(9), e641-648. https://doi.org/10.3109/0142159x.2012.687476

Gough Kenyon, S.M., Lucas, R.M., \& Palikara, O. (2020). Expectations of the transition to secondary school in children with developmental language disorder and low language ability. British Journal of Educational Psychology, 90(2), 249-265. https://doi.org/10.1111/bjep.12292

Health Education England. (n.d.). Practice based learning resources. Retrieved June 29, 2021, from https://www.hee.nhs. uk/our-work/allied-health-professions/increase-capacity/ahppre-registration-student-practice-based-learningprogramme/practice-based-learning-resources

Henkel, M. (2005). Academic identity and autonomy in a changing policy environment. Higher Education, 49(1), 155-176. https:// doi.org/10.1007/s10734-004-2919-1

Henkel, M. (2009). Introduction: Change and continuity in academic and professional identities. In G. Gordon \& C. Whitechurch (Eds.), Academic and professional identities in higher education: The challenges of diversifying a workforce (pp. 3-12). Routledge. https://doi.org/10.4324/9780203865255

Johnson, J., Simms-Ellis, R., Janes, G., Mills, T., Budworth, L., Atkinson, L., \& Harrison, R. (2020). Can we prepare healthcare professionals and students for involvement in stressful healthcare events? A mixed-methods evaluation of a resilience training intervention. BMC Health Services Research, 20(1), 1094. https://doi.org/10.1186/s12913-020-05948-2

Komarraju, M., Musulkin, S., \& Bhattacharya, G. (2010). Role of student-faculty interactions in developing college students' academic self-concept, motivation, and achievement. Journal of College Student Development, 51(3), 332-342. https:// doi.org/10.1353/csd.0.0137

Lawler, S. (2014). Identity: Sociological perspectives (2nd ed.). Polity.

Markowski, M., Bower, H., Essex, R., \& Yearley, C. (2021). Peer learning and collaborative placement models in health care: a systematic review and qualitative synthesis of the literature. Journal of Clinical Nursing, 30(11-12), 1519-1541. https:// doi.org/10.1111/jocn.15661

Mathieson, S. (2014). Student learnng. In H. Fry, S. Ketteridge, \& S. Marshall (Eds.), A handbook for teaching and learning in higher education - enhancing academic practice (4th ed., pp. 63-79). Routledge.

McCormack, G. (2021). The pick 'n' mix practice educator. RCSLT Bulletin, Spring 2021(826), 22-26.

Nelson, H., Hubbard Murdoch, N., \& Norman, K. (2021). The role of uncertainty in the experiences of nurses during the covid19 pandemic: A phenomenological study. Canadian Journal of Nursing Research, 53(2), 124-133. https://doi.org/10.1177/ 0844562121992202

O'Leary, N., \& Cantillon, P. (2020). Why shouldn't we do that on placement if we're doing it in the real world? Differences between undergraduate and graduate identities in speech and 
language therapy. Advances in Health Sciences Education, 25(4), 781-797. https://doi.org/10.1007/s10459-020-09955-0

Pereira, L., Radovic, T., \& Haykal, K.A. (2021, Jun). Peer support programs in the fields of medicine and nursing: a systematic search and narrative review. Canadian Medical Education Journal, 12(3), 113-125. https://doi.org/10.36834/cmej.71129

Peterson, U., Bergström, G., Samuelsson, M., Åsberg, M., \& Nygren, Å. (2008). Reflecting peer-support groups in the prevention of stress and burnout: randomized controlled trial. Journal of Advanced Nursing, 63(5), 506-516. https://doi.org/ 10.1111/j.1365-2648.2008.04743.x

Pettit, A., Stephen, R., \& Nettleton, R. (2015). Developing Resilience in the Workforce: A Health Visiting Framework Guide for Employers, Managers and Team Leaders. http:// www.ewin.nhs.uk/sites/default/files/iHV_Managers\%20Doc ument_AW\%20WEB\%2006\%2005\%20151\%205916.pdf

Quigley, D., Loftus, L., McGuire, A., \& O'Grady, K. (2020). An optimal environment for placement learning: listening to the voices of speech and language therapy students. International Journal of Language \& Communication Disorders, 55(4), 506519. https://doi.org/10.1111/1460-6984.12533

Rogers, R., \& Duffy, O. (2021). An evaluation of a clinicallyproduced simulated case-based online programme on SLT students' transition to placement during COVID-19 restrictions [Paper presentation]. Royal College of Speech and Language Therapists Conference, Virtual.

Royal College of Speech and Language Therapists. (n.d.). Telehealth placement resources. Retrieved June 27, 2021 from https://www.rcslt.org/members/lifelong-learning/practicebased-learning/practice-based-learning-resources/

Salter, C. (2020). Working remotely: Innovative allied health placements in response to COVID-19. International Journal of Work - Integrated Learning, 21(5), 587-600.
Sandiford, J., Hurren, A., \& de Graff, N. (2021). Evaluation of a telehealth model of practice placements from the student and service user perspective [Paper presentation]. Royal College of Speech Language Therapists Conference, Virtual.

Spencer, S., Bishop, S., Churcher, S., Clegg, J., Davies, S., Ellis, R., Fricke, S., Gregory, E., McKinley, D., Pearce, L. \& Rohde, C. (2021) Working with student speech and language therapists to support access to interventions for children with speech, language and communication needs via video calls [Poster presentation]. Royal College of Speech and Language Therapists Conference, Virtual.

Stetson, G.V., Kryzhanovskaya, I.V., Lomen-Hoerth, C., \& Hauer, K.E. (2020). Professional identity formation in disorienting times. Medical Education, 54(8), 765-766. https://doi.org/ 10.1111/medu.14202

Stokes, J., \& McCormick, M. (2015). Speech and language therapy and professional identity: Challenging recieved wisdom. J \& $\mathrm{R}$ Press.

Twogood, R., Hares, E., Wyatt, M., \& Cuff, A. (2020). Rapid implementation and improvement of a virtual student placement model in response to the COVID-19 pandemic. BMJ Open Quality, 9(4), e001107. https://doi.org/10.1136/bmjoq2020-001107

Weaver, R., Peters, K., Koch, J., \& Wilson, I. (2011). 'Part of the team': professional identity and social exclusivity in medical students. Medical Education, 45(12), 1220-1229. https:// doi.org/10.1111/j.1365-2923.2011.04046.x

Wenger, E., McDermott, R.A., \& Snyder, W. (2002). Cultivating communities of practice: A guide to managing knowledge. Harvard Business Press.

West, M.A. (2021). Compassionate leadership: Sustaining wisdom, humanity and presence in health and social care. Swirling Leaf Press. 